\title{
Reconstruction of Comminuted Frontal Bone Fractures by Rib Graft or Titanium Mesh: Assiut University Hospital Experience
}

\author{
SALAH EL-DIEN G. SHALTOUT, M.D.; MOHAMMED H. OSMAN, M.D.; \\ WAEL M. ALI, M.D. and MOHAMMED S. SHAHINE, M.D. \\ The Department of Maxillofacial Surgery, Faculty of Medicine, Assiut University, Assiut, Egypt
}

\begin{abstract}
Background: Frontal bone fractures are one of the common craniofacial fractures [1]. These fractures usually associated with serious complications, such as cerebrospinal rhinorrhea with potential ascending infection, meningeal and intracranial lacerations, obstruction of the lacrimal drainage and nasal airway and oculomotor dysfunction.
\end{abstract}

Aim of Work: To compare the outcome of reconstruction of comminuted frontal bone fractures by rib graft and titanium mesh.

Patients and Methods: This study was carried out on 40 patients with comminuted frontal bone fractures and subdivided into 2 groups, group (I) reconstruction of comminuted frontal bone fractures by rib graft and group (II) reconstruction of comminuted frontal bone fractures by titanum mesh.

Results: Group I: The patients were hospitalized for an average of 12 days.

Patients generally showed remarkable neurologic improvement during their hospital stays, considering the tremendous force of impact. No delayed CSF leaks had occurred at the time of the most recent follow-up (range: 6 months). Good cosmetic results (satisfactory to the evaluating physician and the patient or family) with no gross surface deformities were obtained in 16 patients $(80 \%)$. Group II: The patients were hospitalized for an average of 12 days.

Patients generally showed remarkable neurologic improvement during their hospital stays, considering the tremendous force of impact. No delayed CSF leaks had occurred at the time of the most recent follow-up (range: 6 months). Good cosmetic results (satisfactory to the evaluating physician and the patient or family) with no gross surface deformities were obtained in 18 patients $(90 \%)$.

Conclusion: Autogenous bone grafts such as iliac or rib require a second surgical site. This may lead to donor site morbidity, inability to obtain adequate bone for large defect. The advantages of employing titanium Mesh consist, not only in the optimal stabilization of the fracture, but also in its excellent biocompatibility and in the minimal inflammatory reactions it provokes, as well as the ease with which it adapts

Correspondence to: Dr. Salah El-Dien G. Shaltout, The Department of Maxillofacial Surgery, Faculty of Medicine, Assiut University, Assiut, Egypt to different shapes; furthermore, titanium produces only minimal artifacts on MRI and CT. Disadvantages include infection, limitation of growth and it may fracture and requires time for shaping and curing. The risk of infection may be reduced by adding antibiotic and using it under sterile conditions, beneath well-vascularized skin.

Key Words: Frontal bone fractures - Comminuted rib graft - Titanium mesh - Assiut University.

\section{Introduction}

FRONTAL bone fractures are one of the common craniofacial fractures [1]. These fractures usually associated with serious complications, such as cerebrospinal rhinorrhea with potential ascending infection, meningeal and intracranial lacerations, obstruction of the lacrimal drainage and nasal airway and oculomotor dysfunction [2]. The most common causes of these fractures are motor vehicle accident, assault, falls, sports related injuries, gunshot wounds, and industrial accidents [3]. Improper management of these fractures can result in aesthetic deformity, chronic sinusitis, pneumocephalus, mucopyocels, meningitis and brain abscess [4]. The goals of treatment is protection of intracranial contents, avoidance of short and long term complications as well as the return of aesthetic facial contour [5]. These fractures are classified into simple fractures and comminuted fractures. Reconstruction of comminuted fractures of frontal bone is done either by autogenous graft or synthetic material [6]

\section{Patients and Methods}

This study was carried out on 40 patients with comminuted frontal bone fractures to compare the outcome of reconstruction of comminuted frontal bone fractures by rib graft or titanium mesh.

All patients were admitted to the Trauma unit, Assiut University Hospitals, managed by maxillo- 
facial surgeons and neurosurgeons between August 2015 to May 2017.

\section{Methodology:}

Patients were classified randomly (one by one) into two groups: Group 1 represents patients who treated with rib graft and group II represents patients who treated with titanium mesh.

\section{All patients were subjected to:}

History, Physical examination (generally, neurologically and locally), Laboratory investigations (CBC, prothrombin time and concentration, kidney function tests), Imaging studies (CT and 3DCT scans) are the current imaging standard for evaluating frontal bone fractures. Axial images are helpful in revealing the location, severity, and degree of comminution of anterior and posterior table fractures. Coronal images would reveal fractures of the frontal sinus floor and orbital roof. Sagittal views may facilitate assessing the nasofrontal duct. Gross assessment of dural integrity can be inferred from the presence or absence of pneumocephalus, and Cervical spine and thorax $\mathrm{X}$-rays were carried out in all patients. Other body segments were imaged as needed to exclude or detect other system injuries.

Follow-up of the patients: Clinical, Radiological, and Photography.

Treatment: Urgent surgical treatment was instituted when the patient presented with (1) an open depressed skull fracture, (2) a depressed segment causing significant mass effect, or (3) closed-head intracranial lesion requiring surgical decompression. Attempts were made for elective repair of all other fractures as early as allowed by the general and neurological conditions of the patient (within one week of the trauma). Contraindications for urgent surgical treatment included poor and unstable neurologic function and generally poor medical conditions.

The surgical procedure was performed following some general rules:

Coronal approache which give wide exposure of the fractures; The depressed bone fragments were elevated and the hematoma was evacuated. These steps were followed by intradural operation and dural repair, when needed. The repair of dural lacerations was attempted with primary closure with sutures if feasible. For larger dural tears, pericranium, galea or fascia lata grafts was used for dural closure. Exenteration of the frontal sinus mucosa, cranialization of the sinus, and packing of the bilateral nasofrontal ducts were then accom- plished. Fat graft or muscle was used for this purpose. After the neurosurgical procedure and dural closure, the craniofacial repair was performed. This was done by elevation of bone fragments, reconstruction of bone defects by rib grafts and fixation by miniplates and screws (18 patients) or interosseous wiring ( 2 patients) in group I and titanium mesh in group II.

\section{Postoperative care:}

Postoperative CT scans were obtained to assess bony reconstruction and follow-up intracranial injuries.

\section{Results}

In the present study 36 patients $(90 \%)$ were male and 4 patients (10\%) were females (Table 1). Age of the patients ranged from 20 to 62 years.

\section{Mechanism of injury:}

The causes of injury are listed in Table (2). Motor vehicles accidents accounted for $72.5 \%$ of cases, falls for $17.5 \%$, assaults for $7.5 \%$ and animal kick for $2.5 \%$ of cases. Therefore in most cases injury followed a high velocity trauma.

\section{Treatment:}

\section{Patients groups:}

40 Patients in this study were classified into two groups:

Group I: 20 patients (50\%) who received reconstruction of comminuted frontal bone fractures by rib graft and Group II: 20 patients (50\%) who received reconstruction of comminuted frontal bone fractures by titanium mesh.

\section{Surgical procedures:}

Coronal approaches were used in 18 cases (45\%), translesional (via lacerations) in $22(55 \%)$. The cranial procedures consisted of exenteration of the sinus in 33 patients. Cranialization of the sinuses was necessary in 5 patients. The nasofrontal duct was identified in 36 patients and packed with muscle grafts. The intracranial procedures: Dural repair was performed in 30 patients. Primary dural closure was performed in 26 patients, and 4 patients needed pericranial graft dural closure. Evacuation of extradural hematomas was performed in 2 patients. In 20 cases reconstruction by rib grafts and 20 cases reconstruction by titanium mesh (Table 4).

\section{Postoperative care:}

\section{Group I:}

The patients were hospitalized for an average of 12 days. 
Patients generally showed remarkable neurologic improvement during their hospital stays, considering the tremendous force of impact. No delayed CSF leaks had occurred at the time of the most recent follow-up (range: 6 months). Good cosmetic results (satisfactory to the evaluating physician and the patient or family) with no gross surface deformities were obtained in 16 patients $(80 \%)$. In 2 patient corrugation of the skin at the naso-frontal junction appeared and in another patient an ischemia of a small skin flap occurred. Pleural injury occurred in one patient. The postoperative CT scans generally showed satisfactory bony realignment (Table 5).

\section{Group II:}

The patients were hospitalized for an average of 12 days.

Patients generally showed remarkable neurologic improvement during their hospital stays, considering the tremendous force of impact. No delayed CSF leaks had occurred at the time of the most recent follow-up (range: 6 months). Good cosmetic results (satisfactory to the evaluating physician and the patient or family) with no gross surface deformities were obtained in 18 patients $(90 \%)$. In 2 patient corrugation of the skin at the naso-frontal junction appeared.

The postoperative CT scans generally showed satisfactory results (Table 6).

Table (1): Sex distribution among the studied cases.

\begin{tabular}{lcc}
\hline Sex & No. & Percentage \\
\hline Males & 36 & 90 \\
Females & 4 & 10 \\
\hline Total & 40 & 100 \\
\hline
\end{tabular}

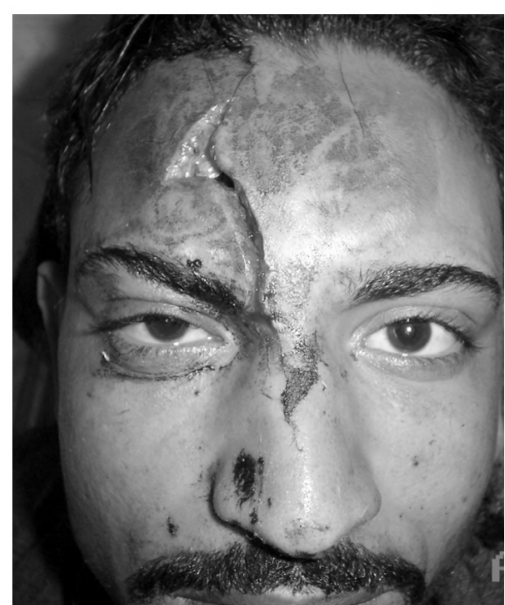

Fig. (A): Clinical photography for the patient immediately after the trauma
Table (2): Mechanism of injury.

\begin{tabular}{lcc}
\hline Cause & No. of patients & Percentage \\
\hline Motor vehicle accident & 29 & 72.5 \\
Fall & 7 & 17.5 \\
Assault & 3 & 7.5 \\
Animal kick & 1 & 2.5 \\
\hline Total & 40 & 100 \\
\hline
\end{tabular}

Table (3): Surgical procedures.

\begin{tabular}{lcc}
\hline Procedure & No. of patients & Percentage \\
\hline Exenteration of sinus mucosa & 33 & 82.5 \\
Cranialization of sinus & 5 & 12.5 \\
Nasofrontal duct packing & 33 & 82.5 \\
Dural repair & 30 & 70.5 \\
Evacuation of EDH & 2 & 5 \\
Base repair by rib grafts & 20 & 50 \\
Base repair by titanium mesh & 20 & 50 \\
\hline
\end{tabular}

Table (4): Postoperative results in group I patients.

\begin{tabular}{lcc}
\hline Postoperative & No. of patients & Percentage \\
\hline Good results & 16 & 80 \\
Skin corrugation & 2 & 10 \\
Skin ischemia & 1 & 5 \\
Infection & 0 & 0 \\
Pleural injury & 1 & 5 \\
\hline Total & 20 & 100 \\
\hline
\end{tabular}

Table (5): Postoperative results in group II patients.

\begin{tabular}{lcc}
\hline Postoperative & No. of patients & Percentage \\
\hline Good results & 18 & 90 \\
Skin corrugation & 2 & 10 \\
Skin ischemia & 0 & 0 \\
Infection & 0 & 0 \\
\hline Total & 20 & 100 \\
\hline
\end{tabular}

\section{Group I}

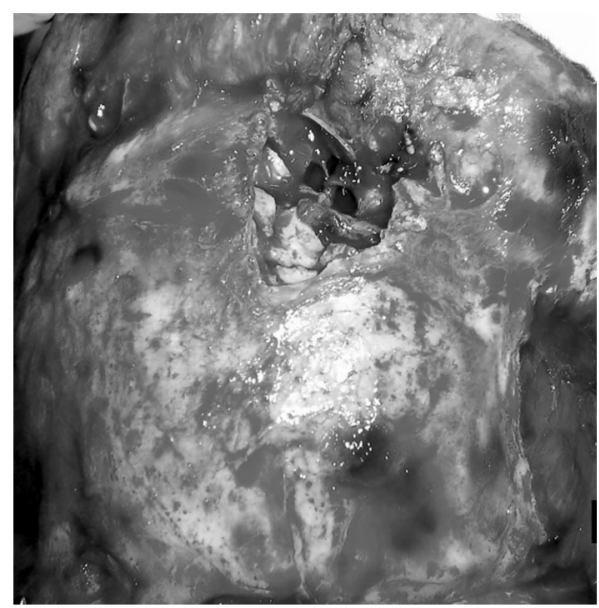

Fig. (B): Intraoperative clinical photography showing the fracture. 


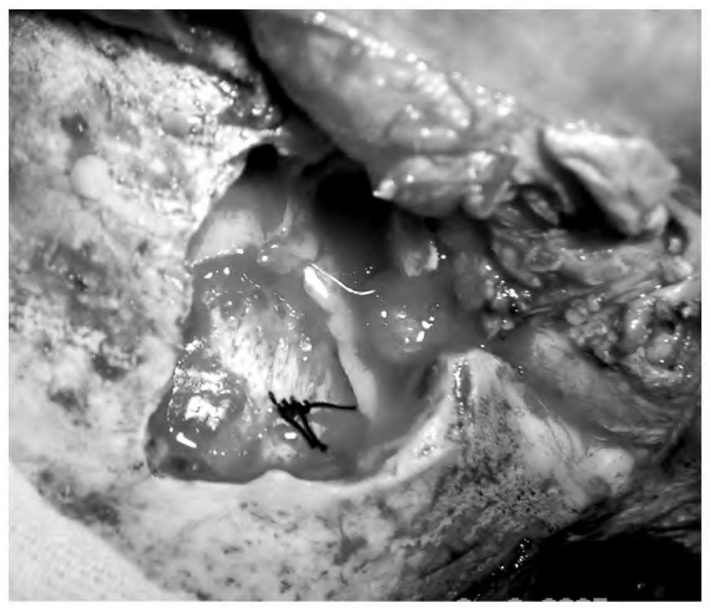

Fig. (C): Intraoperative clinical photography showing repair of the dura.
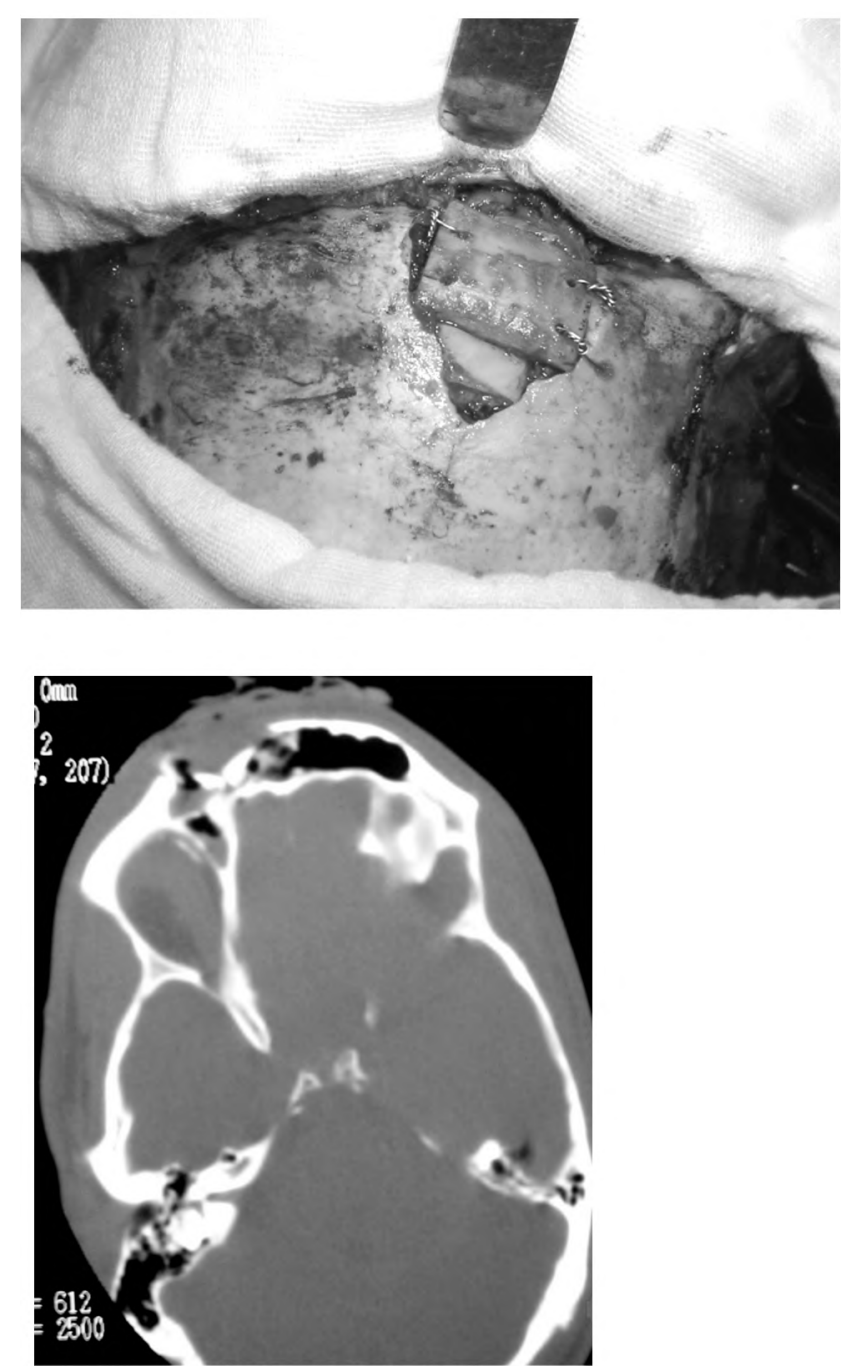

Fig. (F): Preoperative axial CT scan section showing the fracture.

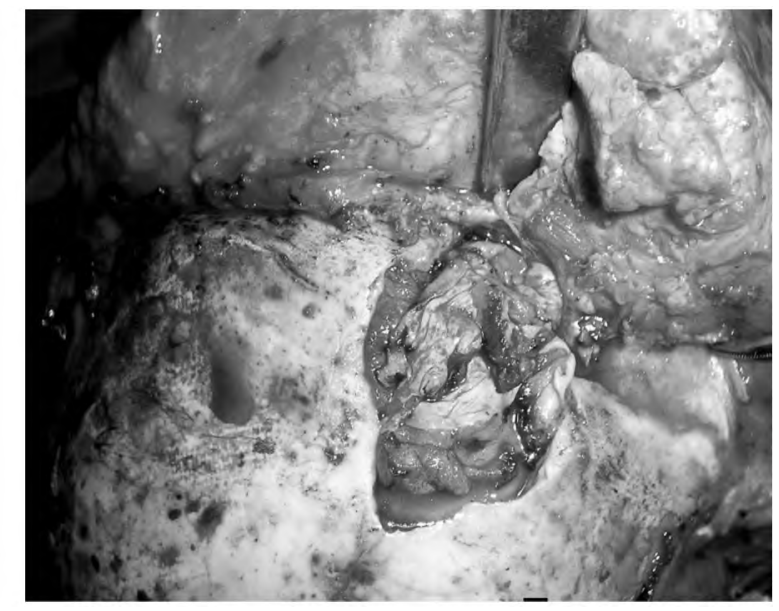

Fig. (D): Intraoperative clinical photography showing blugging of the sinus with muscle and pericranium.

Fig. (E): Intraoperative photography showing a rib graft fixed to the frontal bone defect.

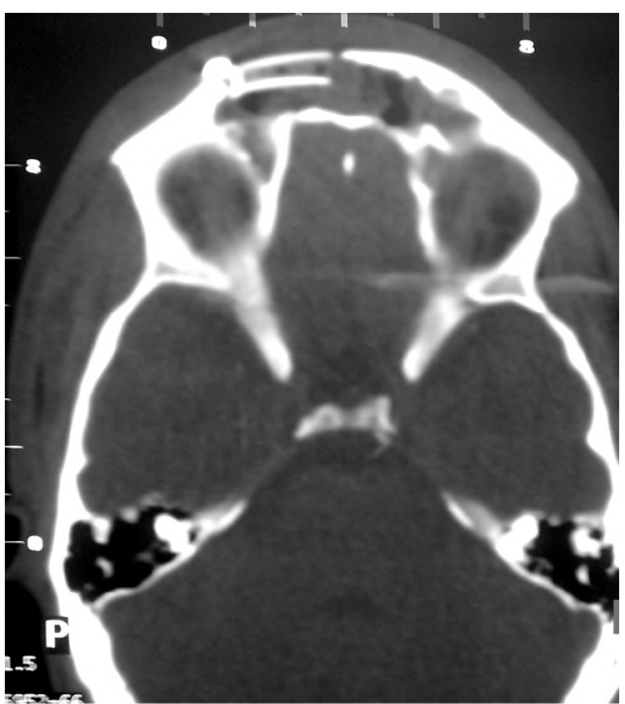

Fig. (G): Post operative axial CT scan section showing the recontouring of the frontal bone. 


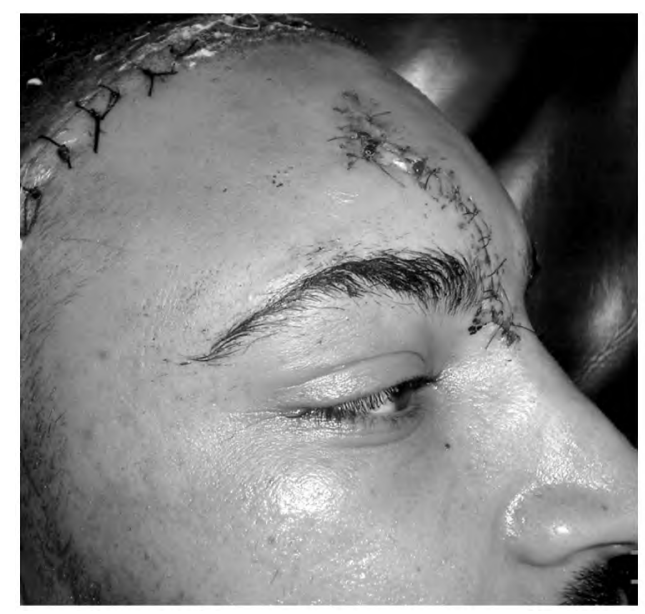

Fig. (H): Post operative clinical photography (after one week), lateral view, showing the recontouring of the frontal bone.

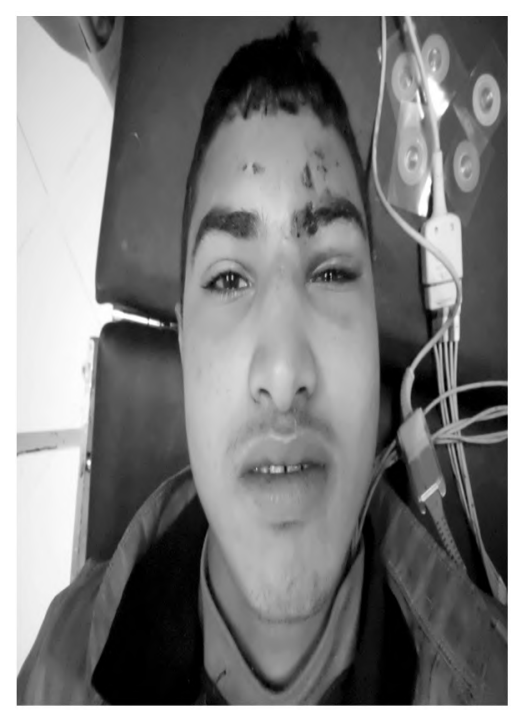

Fig. (A): Preopertive photo.

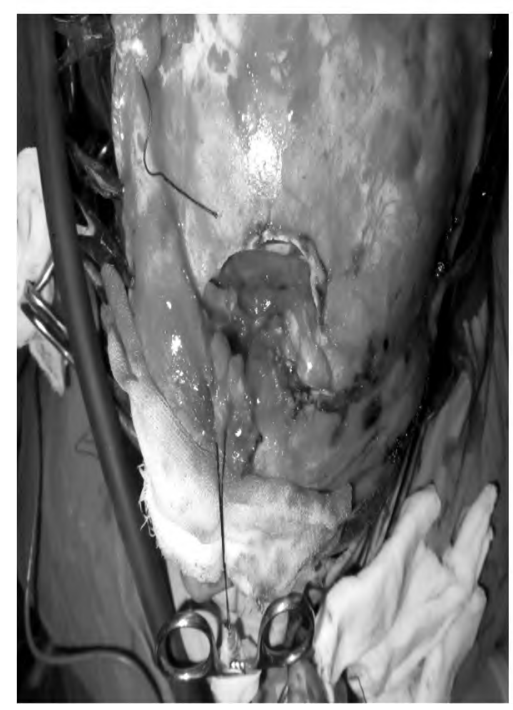

Fig. (C): Intraopertive photo.

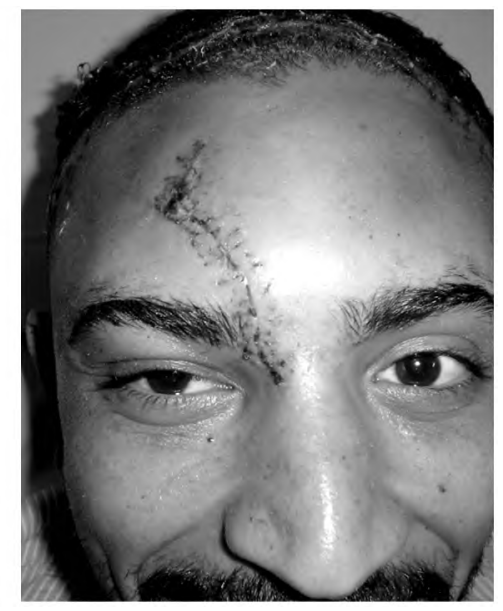

Fig. (I): Post operative clinical photography (after one week): Anterior view.

\section{Group II}

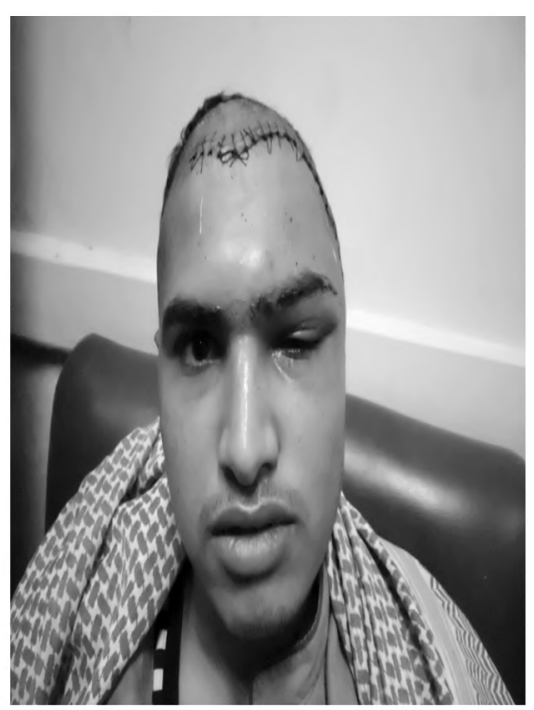

Fig. (B): Postoperative photo.

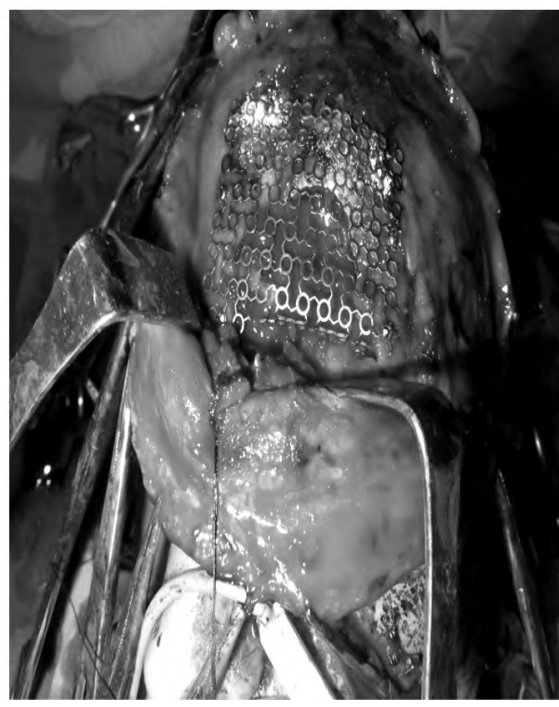

Fig. (D): Intraoperative photo. 


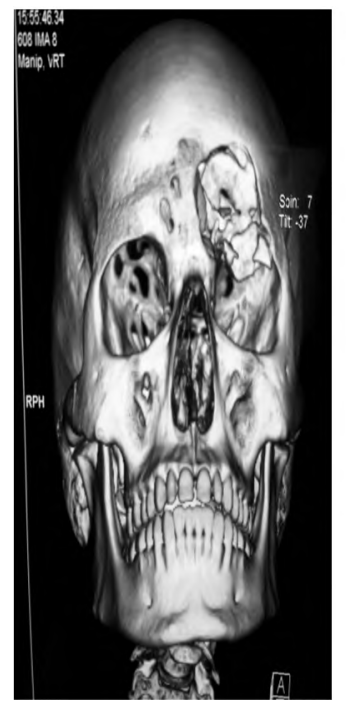

Fig. (E): Preopertive 3D CT scan.

\section{Discussion}

Craniofacial injury has the peculiar feature of involving simultaneously mid and upper face bones, anterior skull base, intracranial structures, and intraorbital content.

High velocity trauma, like motor vehicle accidents, are the most common mechanism of injury. In our series they were found in $73.6 \%$ of patients. Similar rates are reported in other series: Aksoy et al., 2002 [7] reported that, a large amount of frontal impact force is needed to fracture the frontal bone and this is mostly caused by motor vehicle crash, also, Chuang, 2004 [8] reported that: Road traffic accidents represent the major cause of craniofacial fractures, and Donald, 2005 [9] also found that $72 \%$ of the causes of craniofacial fractures are due to motor car accidents. Therefore many patients suffer from severe craniofacial injuries and some can be affected by multisystem injuries due to a polytrauma.

The decision-making process starts with an accurate initial assessment of the patients conditions, looking firstly at the associated intracranial and systemic lesions. Actually some of them are life threatening and need immediate treatment. In a second time the craniofacial lesions are examined. Their assessment will give the information for the next step of the decision making process: The choice of the most appropriate treatment [1].

The development of biomaterials and new techniques in the field of craniofacial sinus surgery has allowed considerable, constant progress in surgical treatment. Reidel Schenke [10] was the first to describe the ablation of the anterior wall

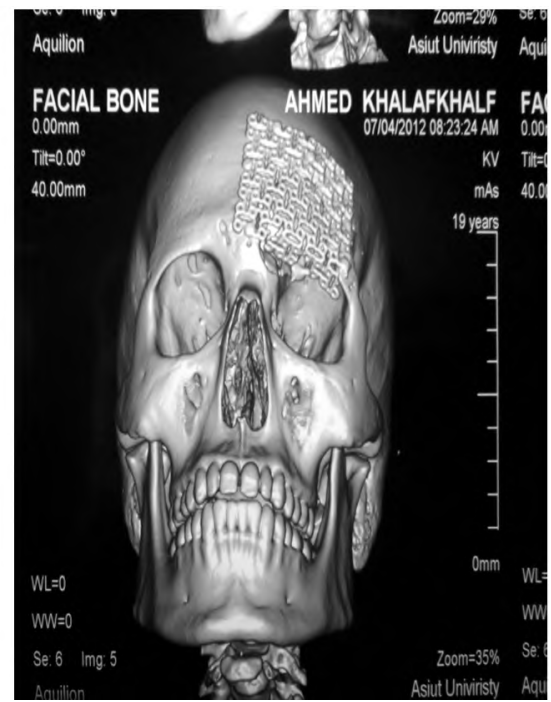

Fig. (F): Postoperative 3D CT scan.

of the frontal sinus. Lynch [11] perfected external frontoethmoidectomy and was the first to insert a catheter in the sinus for prolonged drainage, preserving the frontal bone. Bergara and Itoiz [12] proposed the pericranial flap which replaced the anterior sinus wall and solved the cosmetic problem. Goodale and Montgomery [13] add-ed a further step by removing the mucosal content of the sinus and obliterating the same with autologous fat, noting, together with Stanley [14], a redu-ced rate of infection even with damage to the nasof-rontal duct. Later, other materials were proposed for the obliteration of the sinus: Bone, muscle, fascia. Donald and Bernstein [15] initiated the cranialisation of the frontal sinus, with prolapse of the brain into the sinus cavity in cases of posterior wall fracture. With the exception of emergencies comprising lesions of neurosurgical pertinence, Corina, et al., [16] stated that it is advisable to perform the operation within 24-72 hours of the injury (compatibly with the general condition of the patient), in order to reduce the probability of short and long term complications such as meningitis, cerebral abscesses, rhinoliquorrhoea, mucopyocele and periorbital infections, as this study state.

In this study, 20 cases were reconstructed by rib graft showing satisfactory results in 16 cases and unsatisfactory results in 4 cases with donor site morbidity in one case (pleural injury), as stated by Roberson, et al., [17] who stated that auto-genous bone grafts such as iliac or rib require a second surgical site. This may lead to donor site morbidity, inability to obtain adequate bone for large defect.

In this study, 20 cases are reconstructed by titanium mesh showing satisfactory results in 18 
cases and unsatisfactory results in 2 cases with no infection rate. Lakhani, et al., [18] stated that the advantages of employing titanium mesh consist, not only in the optimal stabilization of the fracture, but also in its excellent biocompatibility and in the minimal inflammatory reactions it provokes, as well as the ease with which it adapts to different shapes; furthermore, titanium produces only minimal artefacts on MRI and CT. Corina, et al., [16] stated that comminuted frontal sinus fractures of the anterior wall require wide surgical exposure by means of a bitemporal coronal incision, and titanium mesh should be considered the material of choice for their repair and fixation. Roberson, et al., [17] stated that advantages of titanium mesh are availability, nonresorbability, ease of surgical procedure, and excellent post operative cosmetic result. Disadvantages include infection, limitation of growth and it may fracture and requires time for shaping and curing. The risk of infection may be reduced by adding antibiotic and using it under sterile conditions, beneath well-vascularized skin.

\section{Summary and conclusion:}

This study was carried out on 40 patients with combined craniofacial fractures to compare the outcome of reconstruction of comminuted frontal bone fractures by rib graft and titanium mesh.

Motor vehicles accidents are the most common cause of frontal bone fractures and accounted for $72.5 \%$ of cases. CT and 3DCT scans are the current imaging standard for evaluating frontal bone fractures. Urgent surgical treatment was instituted when the patient presented with (1) an open depressed skull fracture, (2) a depressed segment causing significant mass effect, or (3) closed-head intracranial lesion requiring surgical decompression. Attempts were made for elective repair of all other fractures as early as allowed by the general and neurological conditions of the patient (within one week of the trauma).

Group I: 20 patients (50\%) who received reconstruction of comminuted frontal bone fractures by rib graft. Good cosmetic results (satisfactory to the evaluating physician and the patient or family) with no gross surface deformities were obtained in 16 patients $(80 \%)$. In 2 patient corrugation of the skin at the naso-frontal junction appeared and in another patient an ischemia of a small skin flap occurred. Pleural injury occurred in one patient. The postoperative CT scans generally showed satisfactory bony realignment.

Group II: 20 patients (50\%) who received reconstruction of comminuted frontal bone fractures by titanium mesh. Good cosmetic results (satisfac- tory to the evaluating physician and the patient or family) with no gross surface deformities were obtained in 18 patients $(90 \%)$. In 2 patient corrugation of the skin at the naso-frontal junction appeared. The postoperative CT scans generally showed satisfactory results. Autogenous bone grafts such as iliac or rib require a second surgical site. This may lead to donor site morbidity, inability to obtain adequate bone for large defect. The advantages of employing titanium Mesh consist, not only in the optimal stabilization of the fracture, but also in its excellent biocompatibility and in the minimal inflammatory reactions it provokes, as well as the ease with which it adapts to different shapes; furthermore, titanium produces only minimal artefacts on MRI and CT. Disadvantages include infection, limitation of growth and it may fracture and requires time for shaping and curing. The risk of infection may be reduced by adding antibiotic and using it under sterile conditions, beneath wellvascularized skin.

\section{References}

1- HELENE MATRAS and HEINZ KUDERNA: Combined Cranio-facial Fractures, J. Max. Fac. Surg., 8: 52-59, 2000.

2- KUTLENBERGER J. and HARDT N.: Long term results following reconstruction of craniofacial defects with titanium micromesh system. J. of Craniomaxillofacial. surg. (Scotland), 29 (2): 75-81, 2001.

3- GHYSEN D, OPSARLA K.O. and VANGOETHEM J.: Maxillofacial trauma, 83 (4): 181-192, 2000.

4- HAUG R.H. and CUNNINGHAM L.L.: Management of fractures of the frontal bone and frontal sinus, Selected Readings in Oral and Maxillofacial Surgery, Vol., 10, No. 6, 2002 .

5- SARGENT L.A. and ROGERS G.F.: Nasoethmoid orbital fractures: Diagnosis and management. J. Craniomaxillofac. Trauma., 5 (1): 19-27, 2000.

6- MOLENDIJK J., VAN DER WAL K.G. and KOUDSTAAL M.J.: Surgical treatment of frontal sinus fractures: the simple percutaneous reduction revised. Int. J. Oral. Maxillofac. Surg. Oct., 41 (10): 1192-4, 2012.

7- AKSOY E., UNLU E., and SENSOZ O.: A retrospective study on the epidemiology and treatment of maxillofacial fractures. J. Craniofac. Surg., 13: 772, 2002.

8- CHUANG S.K.: Evaluation and management of frontal sinus injuries, in Fonseca R.J., Walker R.V., Betts N., Powers M.P., Barber H.D. (eds): Oral and Maxillofacial Trauma. Vol., 2, Ed 3. Philadelphia, PA, Saunders, p 721735,2004

9- DONALD P.J.: Frontal sinus trauma. In: Stewart M.G. (editor). Head, Face, and Neck Trauma. Thieme: New York, p26-37, 2005.

10- RIEDEL SCHENKE H.: Ueber die Stimhohlen und ihre Erkrankungen (inaugural dissertation). Jena, Germany, 1898. 
11- LYNCH R.C.: The technique of a radical frontal sinus operation which has given me the best results. Laryngoscope, 31: 1-5, 1921.

12- BERGARA A.R. and ITOIZ A.O.: Present state of the surgical treatment of chronic frontal sinusitis. Arch. Otolaryngol., 61: 616-28.

13-GOODALE R.L. and MONTGOMERY W.W.: Experiences with osteoplastic anterior wall approach to the frontal sinus. Arch. Otolaryngol., 68: 271-83, 1958.

14- STANLEY R.B.: Fractures of the frontal sinus. Clin. Plast. Surg., 16:115-23, 1989.

15- DONALD P.J. and BERNSTEIN L.: Compound frontal sinus injuries with intracranial penetration. Laryngoscope, 88: 225-32, 1978.

16- CORINA E., SCARANO C., PARRILA G. and ALMADORI G.: PaludattiInstitute of Otolaryngology, Catholic University "Sacro Cuore", Rome Italy, 23: 21-25, 2003.

17- ROBERSON J.B. and ROSENBERG W.S.: Traumatic cranial defects reconstructed with the HTR-PMI cranioplastic implant the J. Craniomaxillofac. Trauma, 3: 8-13, 1997.

18- LAKHANI R.S., SHIBUYA T.Y., MATHOG R.H., MARKS S.C., BURGIO D.L. and YOO G.H.: Titanium mesh repair of the severely comminuted frontal sinus fracture. Arch. Otolaryngol. Head. Neck. Surg., 127: 6659, 2001.

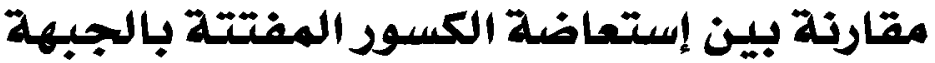

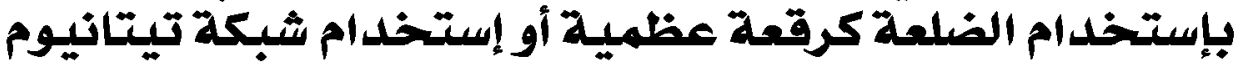

\author{
أجرى هذا البحث على • ع مصاباً والذين تم علاجهم بوحدة الإصابات ورحدة جراحة الوجه والفكين بقسم الجراحة العامة بالمستشفى \\ الجامعى بأسيوط هئ. \\ وتصاحب هذه النوعية من الكسود مضاعفات خطيرة مثل الألتهاب السحائى وإنسداد القناه الدمعية وإنسداد المجرى الهوائى للأنف \\ ومضاعفات للرئيا وتثشوه الوجه. \\ وتمثل حوادث الطريق نسبة 7. \\ وتهدف هذه الدراسة إلى تقييم العلاج المبكر والمتأخر لكسود الوجه والجمجمة. \\ وتراوحت أعمارهم بين • ب سنة وبا عاماً. وقد تم تسجيل التاريخ المرضى مـ عمل الفحص الأكلينيكى وعمل الأبحاث الرتتينية

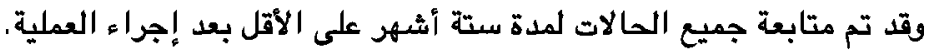

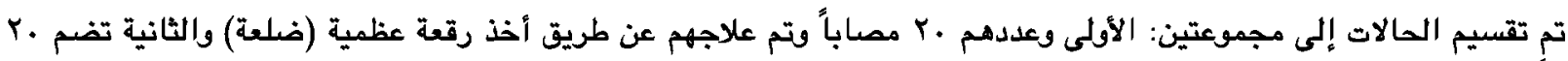 \\ مصاباً وتم علاجهم عن طريق شبكة تيتانيوم. \\ الدراسة أثبتت أن إجراء العملية الجراحية عن طريق ثبكة تيتانيوم أفضل من الضلعة. \\ ويتم أختيار المرضى الذين من الممكن إجراء العملية الجراحية لهم فى مرحلة واحدة على حساب درجة الوعى والأشعة المقطعية.
}

